\title{
Somatostatin-Like Immunoreactivity in Rat Blood
}

\author{
CHARACTERIZATION, REGIONAL DIFFERENCES, AND RESPONSES TO \\ ORAL AND INTRAVENOUS GLUCOSE
}

\author{
M. Berelowitz, S. Kronheim, B. Pimstone, and B. Shapiro, Isotope and \\ Immunoassay Laboratory, Department of Medicine, University of Cape \\ Town, South Africa
}

A в S T R A C T Somatostatin-like immunoreactivity (SLI) has been demonstrated by radioimmunoassay (RIA) in rat serum using an antiserum specific for somatostatin and cross-reacting maximally with the biologically important area on the peptide. The RIA has a sensitivity of $35 \mathrm{pg} / \mathrm{ml}$. SLI dilutes in parallel with synthetic somatostatin standard in the RIA and shows characteristics similar to synthetic somatostatin on Sephadex G-25 (f) gel chromatography eluting largely as a single peak with $1 \mathrm{M}$ acetic acid. Significant regional differences in serum SLI are present. A positive gradient was found in paired samples from aorta (mean \pm SEM, $0.304 \pm 0.024 \mathrm{ng} / \mathrm{ml}$ ) and portal vein $(0.495 \pm 0.047 \mathrm{ng} / \mathrm{ml})$ consistent with the known presence of somatostatin in gut and pancreas, and a negative gradient was noted between paired samples from portal vein $(0.523 \pm 0.076 \mathrm{ng} / \mathrm{ml})$ and hepatic vein $(0.290 \pm 0.048 \mathrm{ng} / \mathrm{ml})$ indicating hepatic clearance. No significant differences were demonstrated between aorta and confluence of cerebral venous sinuses or between aorta and inferior vena cava (IVC). After intragastric glucose, a significant and marked elevation of portal SLI was observed, maximal at $5 \mathrm{~min}(0.416 \pm 0.137$ vs. $1.55 \pm 0.30 \mathrm{ng} / \mathrm{ml}$ at $5 \mathrm{~min}$ ). A significant biphasic elevation of portal SLI also occurred after intravenous glucose. After both routes of glucose administration, the patterns of portal SLI followed closely those of portal glucose and insulin. By contrast, IVC SLI failed to reflect these changes.

Thus, SLI in the rat shows chromatographic similarity with synthetic somatostatin. Regional differences in serum levels are marked; the highest concentrations being found in the portal venous effluent of pancreas and gut. Furthermore, glucose causes elevation of portal SLI in a pattern similar to portal in-

Received for publication 3 January 1978 and in revised form 3 March 1978. sulin and glucose and without concomitant elevation in IVC. This differential elevation of SLI after glucose is consistent with a hormonal action within the portal system as a direct effect of somatostatin on the liver has previously been demonstrated. In addition, the liver is important in the clearance of portal SLI, possibly to prevent extraportal effects in response to gut and pancreatic stimulation. Finally, it is clear that regional sampling of serum for SLI measurement may be critical in the investigation of the putative physiological roles for somatostatin.

\section{INTRODUCTION}

In spite of the reports that exogenously administered synthetic somatostatin reduces fasting blood glucose by a number of putative mechanisms (1) and lowers insulin and glucagon levels (1), its physiologic actions on carbohydrate homeostasis are uncertain. The localization of immunoreactive somatostatin in delta (D) cells of the pancreatic islets, in close apposition to alpha (A) and beta (B) cells, has suggested a local or paracrine role (2) on insulin and glucagon release. That these effects are physiologic is suggested by passive immunization studies which have revealed accentuated insulin (3) and glucagon (4) release from pancreatic islets in the presence of neutralizing somatostatin antiserum. In addition, perfusion of isolated pancreas preparations has consistently revealed somatostatin release into the portal vein effluent in response to glucose and other insulin secretogogues (5).

Using a sensitive radioimmunoassay for somatostatin, we have recently characterized somatostatinlike immunoreactivity $(\mathrm{SLI})^{1}$ in normal human serum (6) and have demonstrated no change in peripheral

\footnotetext{
${ }^{1}$ Abbreviations used in this paper: IV, intravenous; IVC, inferior vena cava; RIA, radioimmunoassay; SLI, somatostatinlike immunoreactivity.
} 
venous SLI after oral or intravenous (IV) glucose (7), suggesting that either SLI was not released in response to glucose in man or that portal venous SLI elevations were not reflected in peripheral blood.

In this communication, we describe the presence and characterization of SLI in regional blood samples in the rat and changes of portal venous and inferior vena caval serum SLI after intragastric and intravenous glucose. A report of high portal and unchanged inferior vena caval SLI after intravenous glucose in dogs has recently appeared, although detailed characterization of SLI was not performed (8).

\section{METHODS}

Experiments were performed using adult male long-Evans rats weighing 225-325 g, housed under constant conditions, and fasted overnight with free access to water. All studies were performed under controlled $5 \%$ ether anesthesia. Blood samples were taken into aprotinin $500 \mathrm{KIU} / \mathrm{ml}$ (Trasylol, FBA Pharmaceuticals, Inc., New York), placed immediately on ice, and serum was then separated by centrifugation at $10^{\circ} \mathrm{C}$ and stored at $-20^{\circ} \mathrm{C}$ until assay.

Regional sampling. Blood was sampled simultaneously from inferior vena cava (IVC) and aorta, aorta and portal vein, portal and hepatic veins, and aorta and the confluence of cerebral venous sinuses (by aspiration through the cranium) from 12 pairs of rats for each comparison.

Glucose tolerance tests. (a) Intragastric: Conscious rats received $1 \mathrm{ml}$ of $50 \%$ dextrose water or physiological saline per $100 \mathrm{~g}$ body wt via an intragastric tube. Basal blood samples were obtained in rats after intragastric intubation, but before dextrose or saline administration. Blood was sampled simultaneously from the portal vein and IVC from five animals at each point in time, i.e. basally and 5 , 10 (glucose only), 30, and $60 \mathrm{~min}$ after glucose or saline. (b) Intravenous: Rats received $1 \mathrm{ml} / 100 \mathrm{~g}$ body wt $12.5 \%$ dextrose-water or physiological saline intravenously via a tail vein. Basal and post glucose or saline sampling were identical to those receiving intragastric solutions.

Immunoassay procedures. Somatostatin was estimated by radioimmunoassay (RIA) (9) using a rabbit anti-somatostatinhemocyanin serum $\left(1: 125,000\right.$ final dilution), ${ }^{125}{ }^{25}-$ Tyr$^{1}$ somatostatin (sp act $750 \mu \mathrm{Ci} / \mu \mathrm{g}$ ) prepared by the chloramine-T technique and purified by CM52 cellulose chromatography, Ayerst AY24910 synthetic somatostatin reference preparation (Ayerst Laboratories, New York), and a dextrancoated charcoal separation of antibody-bound from free tracer. The antiserum shows no cross-reaction with a wide variety of naturally occurring peptide hormones (including secretin and glucagon which share the peptide sequence, $\mathrm{Thr}$ Phe-Thr-Ser), and neurotransmitters (9), good cross-reactivity with des-Ala ${ }^{1}-G_{1}{ }^{2}$ somatostatin, Tyr ${ }^{1}$-somatostatin, a cyclic form of tetrapeptide 4-13 somatostatin (all of which inhibit growth hormone), and no cross-reactivity with bio-inactive $\mathrm{D}-\mathrm{Phe}^{6}, \mathrm{D}-\mathrm{Phe}^{7}, \mathrm{Phe}^{8}$, or $\mathrm{Pro}^{8}$ substituted somatostatin. This suggests a locus of cross-reactivity away from the $\mathrm{N}$-terminus and, at least in part, related to amino acids 6-8, regarded as a biologically important area in respect of growth hormone inhibition. The assay has a sensitivity of $35 \mathrm{pg} / \mathrm{ml}$ and an inter- and intraassay variation of 15 and $13 \%$, respectively. Glucose was measured by the glucose oxidase method of Lavine et al. (10), immunoreactive insulin by RIA using guinea pig anti-porcine insulin antiserum (Burroughs Wellcome, Beckenham, Kent, England) and crystalline rat insulin standard (Novo Research Institute, Copenhagen, Denmark) by the method of Weinkove et al. (11), and glucagon by RIA using Unger $30 \mathrm{~K}$ antiserum (courtesy Dr. A. Vinik, University of Cape Town).

Methods for characterization of SLI. Incubation damage to ${ }^{125} \mathrm{I}-\mathrm{T}_{\mathrm{yr}}{ }^{1}$-somatostatin by serum from the areas sampled was estimated by chromatoelectrophoresis on three occasions as previously described (12) after an overnight incubation at $4^{\circ} \mathrm{C}$ of serum or assay buffer and tracer in the proportions utilized in the somatostatin RIA. The recovery of $1 \mathrm{ng}$ of synthetic cyclic somatostatin added to sera of measured SLI content was estimated from all regions sampled.

Sera from portal vein $(n=8)$, aorta $(n=9)$, IVC $(n=4)$, hepatic vein $(n=4)$, and confluence of sinuses $(n=4)$ were measured in the serial dilutions for comparison with the slope of the dilution curve of synthetic cyclic somatostatin.

Sephadex G-25(f) gel chromatography of $2-\mathrm{ml}$ serum samples from all regions except for IVC (from which $4 \mathrm{ml}$ of serum was lyophilized and reconstituted in $2 \mathrm{ml} 1 \mathrm{M}$ acetic acid) was performed in $1 \mathrm{M}$ acetic acid as previously described (6). $5 \mathrm{ng}$ of synthetic cyclic somatostatin eluted under the same conditions acted as a marker, dextran blue being used to measure the void volume. All fractions were lyophilized and reconstituted in assay buffer before somatostatin RIA.

Statistical analysis of data was performed using the Wilcoxon unpaired rank test (Mann-Whitney) and the Student's $t$ test for paired samples.

\section{RESULTS}

Characterization of rat serum SLI. ${ }^{125} \mathrm{I}_{-} \mathrm{T} y \mathrm{r}^{1-}$ somatostatin in serum (89.8\% intact) showed no damage in excess of that seen in assay buffer $(90.5 \%$ intact) over the duration of the immunoassay at $4^{\circ} \mathrm{C}$. Good recoveries of synthetic cyclic somatostatin were obtained in serum from all the areas studied, ranging from 86.7 to $92.4 \%$. Serial dilutions of serum SLI showed parallelism to synthetic standard (Fig. 1) in all the regions studied.

SLI eluted on Sephadex G-25(f) in a single major peak in all the sera studied (Fig. 2) showing identity with the elution profile of synthetic cyclic somatostatin. A small amount of immunoreactive material eluted in a single fraction in the void volume in sera from all the regions sampled except portal vein. A recovery of $40-60 \%$ of the added immunoreactivity was eluted from the columns.

Regional vascular sampling (mean \pm SEM, each comparison comprising 12 pairs). A significant positive SLI concentration gradient $(P<0.005)$ was found (in sera sampled simultaneously) between the aorta $(0.304 \pm 0.024 \mathrm{ng} / \mathrm{ml})$ and portal vein $(0.495 \pm 0.047$ $\mathrm{ng} / \mathrm{ml})$ and negative gradient $(P<0.05)$ between the portal vein $(0.523 \pm 0.076 \mathrm{ng} / \mathrm{ml})$ and hepatic vein $(0.290 \pm 0.048 \mathrm{ng} / \mathrm{ml})$. No significant gradient was demonstrated between aorta $(0.343 \pm 0.025 \mathrm{ng} / \mathrm{ml})$ and confluence of sinuses $(0.363 \pm 0.025 \mathrm{ng} / \mathrm{ml})$ or between aorta $(0.354 \pm 0.044 \mathrm{ng} / \mathrm{ml})$ and IVC $(0.322 \pm 0.073$ $\mathrm{ng} / \mathrm{ml})$.

Glucose tolerance tests (Fig. 3). After intragastric 


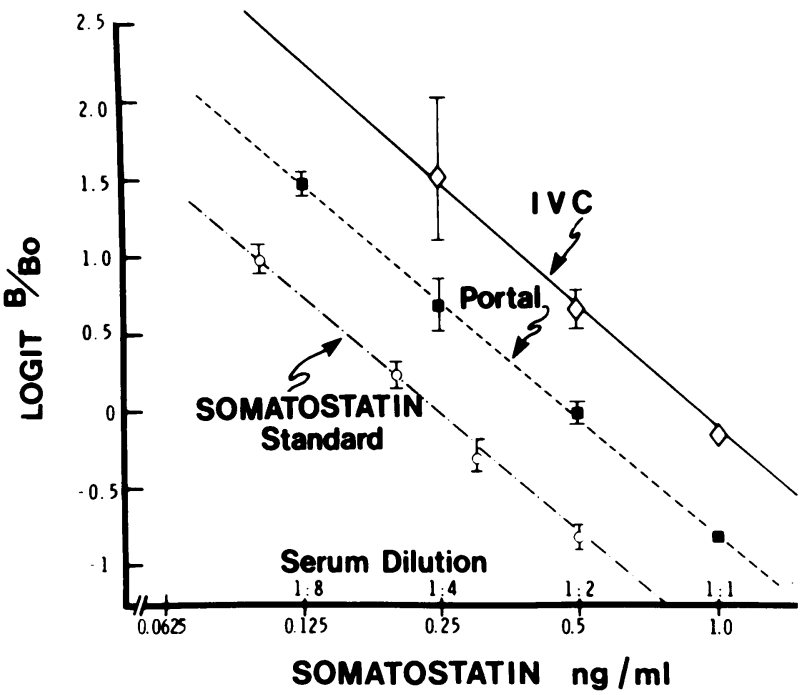

Figure 1 Logit-log plots of serial dilutions of serum from the portal vein (portal: $y=-2.53 x+4.24, r=0.9997$ ) and inferior vena cava (IVC: $y=-2.64 x+5.40, r=0.9997$ ) showing parallelism with the tracer displacement slope derived from decreasing amounts of synthetic somatostatin ( $y$ $=-2.59 x+1.612)$. Not shown for clarity are serial dilutions of serum from hepatic vein $(y=-2.69 x+6.07, r$ $=0.9999)$, aorta $(y=-2.52 x+4.70, r=0.997)$ and confluence of the cerebral venous sinuses $(y=-2.60 x+4.74$, $r=0.9997)$ which exhibited similar parallelism.

glucose, portal SLI rose significantly from 0.416 $\pm 0.137 \mathrm{ng} / \mathrm{ml}$ basally to $1.59 \pm 0.30 \mathrm{ng} / \mathrm{ml}$ at $5 \mathrm{~min}$ and $1.17 \pm 0.24 \mathrm{ng} / \mathrm{ml}$ at $10 \mathrm{~min}$ coinciding with the maximal glucose and insulin elevations. No corresponding change was seen in the IVC bloods simultaneously sampled.

A lesser but significant biphasic elevation of SLI was noted in portal venous serum after IV glucose, significant at 10 and $60 \mathrm{~min}$ corresponding to the biphasic insulin responses.

No significant changes of glucose, insulin, glucagon, and SLI followed oral or IV saline.

\section{DISCUSSION}

The presence of somatostatin immunoreactivity in $\mathrm{D}$ cells of the pancreatic islets, in close approximation to the cells secreting insulin and glucagon (2), together with the inhibitory effects of synthetic somatostatin on pancreatic insulin and glucagon release (1) and the increase in pancreatic insulin (3) and glucagon (4) secretion after neutralization of endogenous somatostatin by anti-somatostatin serum suggest a role for the peptide in carbohydrate homeostasis. In addition, in vitro studies have indicated that SLI is released from the pancreas in response to glucose and a number of other insulin secretogogues (5), suggesting that somatostatin re- lease from the pancreas may occur under physiologic conditions.

Using a well-characterized RIA (9), we have previously described studies on the occurrence and characterization of SLI in human serum (6). Human SLI shares immunological identity with synthetic somatostatin as demonstrated using affinity chromatography; identity with synthetic cyclic somatostatin is further suggested by parallelism on serial dilutions and identical mobility on thin-layer and Sephadex G-25(f) gel chromatography.

In this communication we have validated the somatostatin RIA for rat serum. That the material measured as somatostatin in the assay is not an artifact due to label degradation has been excluded by studies showing minimal incubation damage, no greater than induced by the assay buffer. Good re-

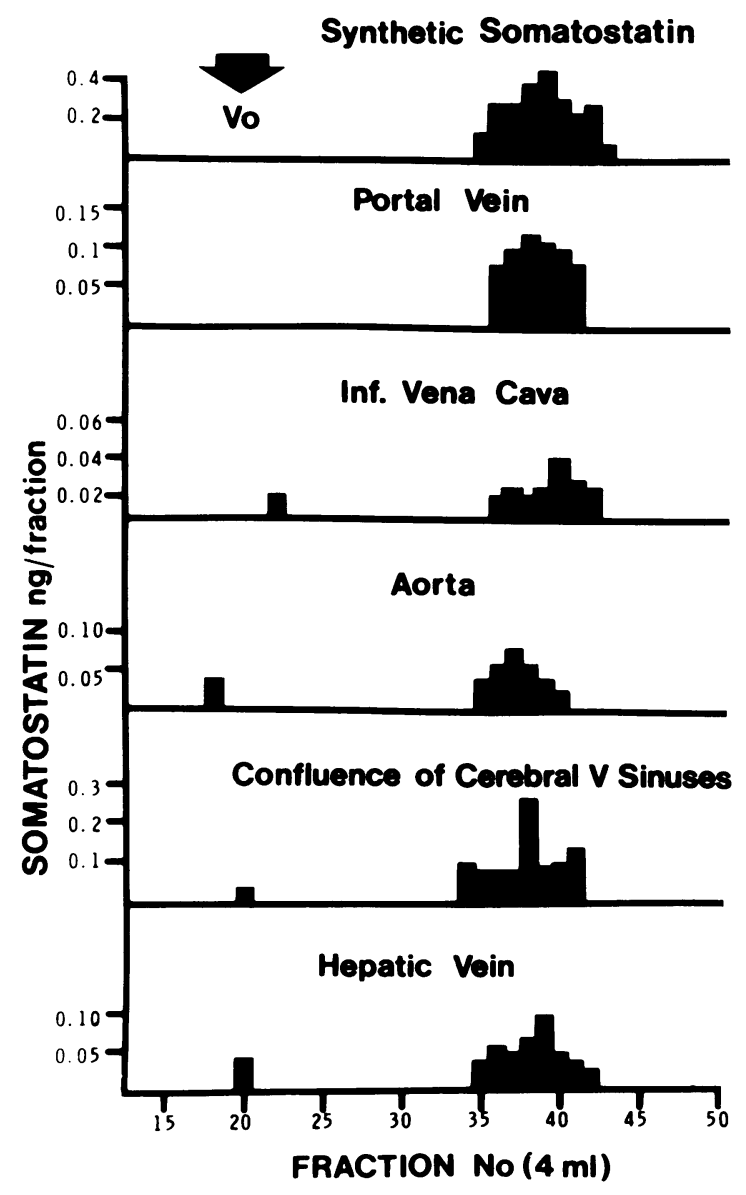

FIGURE 2 Elution profiles of synthetic somatostatin (Ayerst AY24910) and serum SLI from portal vein, hepatic vein, IVC, confluence of cerebral venous sinuses and aorta on a Sephadex G-25(f) column $(90 \times 1.6 \mathrm{~cm}$, flow rate $30 \mathrm{ml} / \mathrm{h}$ ), eluting with $1 \mathrm{M}$ acetic acid. A recovery of $40-60 \%$ of synthetic somatostatin or serum SLI was obtained. $V_{0}$, void volume. 


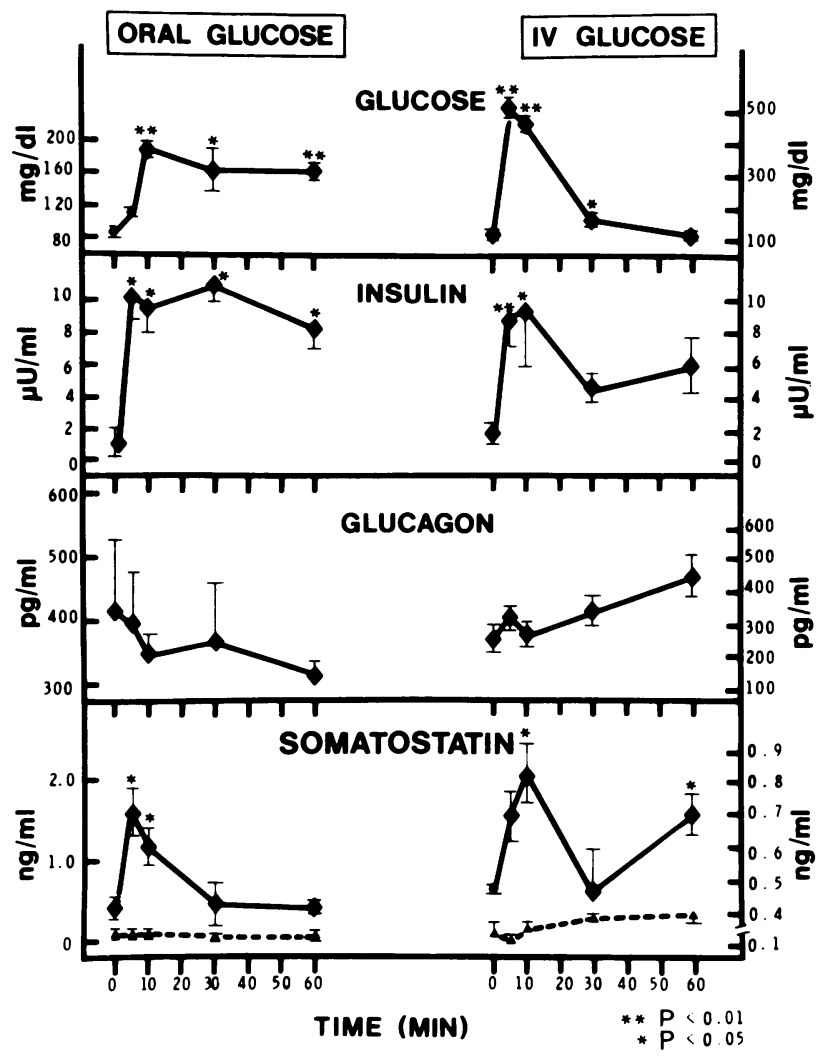

Figure 3 Serum glucose, insulin, glucagon, and SLI responses to intragastric or IV glucose in portal venous blood $(-)$ and inferior vena cava (-- ). Statistically significant differences from basal values are indicated by $*(P<0.05)$ or $* *(P<0.01)$.

coveries of added synthetic cyclic somatostatin were obtained from sera from all the vessels studied confirming that somatostatin is stable in serum containing Trasylol. The demonstration that serial samples of serum diluted out in parallel with the standard curve is consistent with, though not proof of identity. The gel elution profiles of the serum immunoreactivity and synthetic somatostatin on Sephadex G-25(f) using $1 \mathrm{M}$ acetic acid were similar in all the samples studied, most of the immunoreactivity appearing in a single peak $(R f=0.83)$. Whether serum SLI in human or the rat is identical with tissue somatostatin will only be answered by studies of the chemical structure and biologic characterization of the circulating peptide.

Glucose given orally or intravenously failed to influence peripheral venous serum SLI in 10 human subjects studied during an investigation into the effects of nutrient stimuli on serum SLI (7) suggesting that portal blood sampling might more accurately reflect the relevant physiological situation in pancreas or gut.
Paired blood samples simultaneously obtained from various regions in fasted rats do, in fact, reveal positive aortic-portal vein and negative portal-hepatic vein gradients. This implies that active secretion or passive release of somatostatin occurs from the gut or pancreas and may not be reflected in peripheral blood. More specific portal vascular samplings were not possible in this study and the precise gastrointestinal source cannot be identified, though it has recently been shown in the dog that the major gradient is pancreatic vein-IVC (8).

After intragastric and intravenous glucose, no change was seen in peripheral (IVC) SLI levels, yet a highly significant rise occured in portal vein SLI following both stimuli, higher levels being achieved after the intragastric glucose, demonstrating close temporal correlation with portal glucose and insulin. Recent work in dogs has shown comparable results to those we report in this study (8) although nonparallelism between serum immunoreactivity and synthetic standard was found, and no characterization was reported. However basal and post-IV glucose IVC and portal venous SLI levels were very similar to those we find.

Somatostatin, at least in pancreatic islets, is thought to have a local modulating effect on insulin and glucagon secretion (2). This postulate is based on the anatomical proximity of somatostatin-, glucagon-, and insulin-secreting cells (2), but also on the observation of elevated pancreatic SLI associated with diminished insulin and high glucagon in streptozotocin diabetic rats (13), and the conversely low pancreatic SLI and high insulin in the obob mouse (14). The presence of SLI in the portal vein in higher concentration than in the periphery suggests that it might have an additional physiological hormonal role, at least within the portal circulation; selective elevation of portal SLI after glucose would support this, particularly in view of a direct inhibitory effect of synthetic somatostatin on hepatic glucose release found in the isolated perfused rat liver (15). Apart from this consideration, the liver must play an important role in SLI clearance in view of the marked negative gradient across that organ. This may represent a mechanism whereby biologic effects of somatostatin released from pancreas or gut can be compartmentalized within the portal system in view of the widespread inhibitory effects of this peptide. Finally, the gradients existing across the gut and liver suggest that regional sampling will provide an important means of studying the responses to physiologic manipulation.

Though final identification of the measured immunoreactivity as being somatostatin is not available, studies of the precise chemical nature and biological characteristics of SLI and further observations of the responses in physiological and pathological situa- 
tions, may provide further insight into somatostatin physiology.

\section{ACKNOWLEDGMENTS}

Financial support for this study was received from the South African Medical Research Council and Atomic Energy Board, International Atomic Energy Agency Grant 1806/RB, University of Cape Town Staff Research Fund, Nellie Atkinson Bequest, and Harry Crossley Foundation.

\section{REFERENCES}

1. Felig, P., J. Wahren, R. Sherwin, and R. Hendler. 1976. Insulin, glucagon, and somatostatin in normal physiology and diabetes mellitus. Diabetes. 25: 1091-1099.

2. Orci, L., and R. H. Unger. 1975. Functional subdivision of islets of Langerhans and possible role of D cells. Lancet. II: $1243-1244$.

3. Taniguchi, H., M. Utsumi, M. Hasegawa, T. Kobayashi, Y. Watanabe, K. Murakami, M. Seki, A. Tsutou, H. Makimura, M. Sakoda, and S. Baba. 1977. Physiologic role of somatostatin: insulin release from rat islets treated by somatostatin antiserum. Diabetes. 26: 700-702.

4. Barden, N., M. Lavoie, A. Dupont, J. Côté, and J-P. Côté. 1977. Stimulation of glucagon release by addition of anti-somatostatin serum to islets of Langerhans in vitro. Endocrinology. 101: 635-638.

5. Schauder, P., C. McIntosh, J. Arends, R. Arnold, H. Frerichs, and W. Creutzfeldt. 1976. Somatostatin and insulin release from isolated rat pancreatic islets stimulated by glucose. FEBS (Fed. Eur. Biochem. Soc.) Lett. 68: $225-227$.
6. Kronheim, S., M. Berelowitz, and B. L. Pimstone. 1978 The characterisation of somatostatin-like immunoreactivity in human serum. Diabetes. In press.

7. Pimstone, B., M. Berelowitz, D. Kranold, B. Shapiro, and S. Kronheim. 1978. Somatostatin-like immunoreactivity SRIF-LI) in human and rat serum. Metab. Clin. Exp. In press.

8. Schusdziarra, V., R. E. Dobbs, V. Harris, and R. H. Unger. 1977. Immunoreactive somatostatin levels in plasma of normal and alloxan diabetic dogs. FEBS (Fed. Eur. Biochem. Soc.) Lett. 81: 69-72.

9. Kronheim, S., M. Berelowitz, and B. L. Pimstone. 1976 A radioimmunoassay for growth hormone releaseinhibiting hormone: method and quantitative tissue distribution. Clin. Endocrinol. 5: 619-630.

10. Lavine, R. L., W. L. Chick, A. A. Like, and T. W. Makdisi. 1971. Glucose tolerance and insulin secretion in neonatal and adult mice. Diabetes. 20: 134-139).

11. Weinkove, C., E. A. Weinkove, and B. L. Pimstone. 1974 Micro assays for glucose and insulin. S. Afr. Med. J 48: $365-368$.

12. Kronheim, S., M. Berelowitz, and B. L. Pimstone. 1977. The characterization of growth hormone release inhibiting hormone-like immunoreactivity in normal urine. Clin. Endocrinol. 7: 343-347.

13. Patel, Y. C., and G. C. Weir. 1976. Increased somatostatin content of islets from streptozotocin-diabetic rats. Clin. Endocrinol. 5: 191-194.

14. Patel, Y. C., L. Orci, A. Bankier, and D. P. Cameron. 1976. Decreased pancreatic somatostatin (SRIF) concentration in spontaneously diabetic mice. Endocrinology. 99: $1415-1418$.

15. Sacks, H., K. Waligora, J. Mathews, and B. Pimstone 1977. Inhibition by somatostatin of glucagon-induced glucose release from the isolated perfused rat liver. Endocrinology. 101: 1751-1759. 